\title{
Optimal Activity Times and Habitat Choice of Moose
}

\author{
Gary E. Belovsky ${ }^{1}$ \\ Society of Fellows, Harvard University, 78 Mt. Auburn St., Cambridge, MA 02138
}

\begin{abstract}
Summary. A set of concepts was presented which could be used to model an animal's activity cycle and habitat choice as an optimization process. The model was applied to moose (Alces alces) summer activity and its predictions were consistent with observed feeding times and habitat selections. The optimization model had a goal of maximizing daily feeding time at the least possible energetic cost. This goal was consistent with a foraging strategy that maximized the intake of some nutritional component, i.e. energy, protein, etc. The optimization problem, however, was bounded. Three constraints appeared to limit the goal: body temperature must be maintained within set upper and lower limits, thermal equilibrium must be maintained over an extended period so the activity cycle strategy can be repeated and sufficient time must be spent ruminating.
\end{abstract}

Naturalists have long been aware that animals demonstrate daily activity cycles; this paper attempts to demonstrate that these cycles and associated hourly changes in habitat use result from an optimization process, which balances the goals of maximizing feeding time and minimizing risks. Risks are posed to animals by predators and the inability to maintain internal homeostasis (i.e. thermal balance, water turnover, etc.). The moose (Alces alces) is an ideal test case for several reasons. First, moose, as herbivores, have activity cycles which are not tied to prey activity cycles, since plants are sessile. Second, as large animals, moose are not capable of burrowing or using microhabitats to avoid the ambient environment, and are relatively predator-free. Thus risks are restricted to breakdowns in internal homeostasis.

Optimization models for determining daily feeding time are inseparably tied to foraging strategy theory (Schoener 1971; Pyke et al. 1977). An animal has two alternatives in determining daily feeding time. First, if the animal is maximizing its intake of some nutritional component (synonymous with an energy-maximizing feeding strategy), it should attempt to maximize daily feeding time. This strategy provides an animal with greater food supplies, since items of lower quality can profitably be consumed (Schoener 1969), and more food can be consumed each day. Nevertheless, an animal can not feed all day, since its digestive organ can only hold so much food and the environment presents many deliterious factors (predation, excessive heat gains and losses, dessication, etc).

1 Present address: School of Natural Resources University of Michigan Ann Arbor, MI 48109
Second, an animal might minimize its daily feeding time, while still attaining nutritional requirements. This is synonymous with a time-minimizing feeding strategy. While feeding-time-maximization increases resources for reproduction and times of scarcity, time-minimization provides more time for non-feeding activities: i.e. reproduction and grooming, and minimizes exposure to deliterious factors in the environment.

If an animal was a time-minimizer, it would feed until its nutritional requirements were satisfied and only at times that posed the least risk. After feeding, the animal would retire to habitats that posed the least risk. On the other hand, a feeding-time-maximizer would balance the benefits of feeding in each period against the risks, assuming that the digestive organ was not full. Furthermore, while not feeding, the animal would perform behaviors in habitats which not only minimized risks but allowed a return to feeding as soon and for as long as possible.

Moose at Isle Royale, Michigan, were faced with the feedingtime-maximization problem since they were known to be energy maximizers in their feeding (Belovsky 1978). Furthermore, it appeared that the risk while feeding was a breakdown of thermal homeostasis; feeding was associated with cooler and less sunny periods of the day and the amount of time spent feeding on a summer day was highly correlated with daily average temperature (Belovsky and Jordan 1978). This was not to imply that air temperature was the determinant of feeding in itself, rather it was an easily measured thermal parameter which was seasonally correlated in the field with other, perhaps more important but more difficult to measure, parameters: i.e. solar radiation (see Appendix). Dessication was not thought to be an alternative explanation since moose ingested 28.71/day of water in food (Belovsky 1978) and environmental water was abundant.

The thermal imbalances experienced by moose performing different behaviors in various habitats at different times of the day had to be quantified. These behavior-habitat-time choices and their resulting thermal imbalances were incorporated in an optimization model which maximized daily feeding time at the least possible energetic cost and within tolerances to thermal imbalances. If two alternative sets of behavior-habitat-time choices gave the same daily feeding time, but at different energetic costs, the least costly would be selected (Belovsky 1978). The optimization technique employed was dynamic programming (Bellman and Dreyfus 1962). The solution provided a prediction of a moose's choice of behavior and habitat at each hour of an average summer day, given the potential choices set forth in the model. These could be compared to the observed habitat-behavior choices observed in the field. 


\section{Methods and Model}

\section{Methods}

The summer (June-September) behavior of moose was studied at Isle Royale National Park, Michigan, from 1972 to 1974. These investigations provided information on a moose's hourly choice of behaviors and habitats through direct observation (Belovsky and Jordan 1978) and radio-telemetry. Direct observation provided data on times of the day and habitats that moose used while feeding, along with other feeding parameters, and were presented elsewhere with a habitat description (Belovsky and Jordan 1978).

Of 8 moose radio-collared, 5 did not provide data because their radios malfunctioned or they left the study site. The 3 successfully radio-collared moose were used to determine distances traversed hourly, average habitat utilization and hourly-habitat utilization. The hourly-distances were based upon the line joining locations obtained initially and an hour later, as such they represented a minimum distance traversed. By locating a cow moose at each hour of the day over three different days and plotting these locations on a habitat map, the number of observations in each habitat was determined as well as their regularity with time of day. Air temperature measurements were made simultaneously with all direct and radio-telemetered observations.

The environment was sampled randomly for bed remnants, which appeared as depressed vegetation. This was done by walking transects for a fixed distance and direction from a starting point chosen using random numbers and a map grid. Each bed was classified by habitat and orientation, whether the long axis of the depressed vegetation, length of moose body, was parallel or perpendicular to the sun's path. A perpendicular orientation maximizes the solar radiation striking a moose, while a parallel attitude minimizes solar radiation.

Thermal imbalances experienced by an average adult moose for hourly behavior-habitat choices during an average summer day were computed using a simple thermodynamic model of heat flow between an animal and its environment (Porter and Gates 1969):

$H S=M+Q_{\mathrm{abs}}-\gamma \varepsilon T_{\mathrm{r}}^{4}-h_{\mathrm{c}}\left(T_{\mathrm{r}}-T_{\mathrm{a}}\right)-E_{\mathrm{ex}}-E_{\mathrm{sw}} \pm C$

where $H S$ is heat stored by the animal's body $\left(\mathrm{Wm}^{-2}\right), M$ is the metabolic heat produced by the animal $\left(\mathrm{Wm}^{-2}\right), Q_{\mathrm{abs}}$ is the solar radiation absorbed by the animal $\left(\mathrm{Wm}^{-2}\right), \gamma$ is the StefanBoltzman constant $\left(\mathrm{Wm}^{-2} /{ }^{\circ} \mathrm{K}^{4}\right), \varepsilon$ is the emissivity of the animal's surface, $T_{\mathrm{r}}$ is the animal's surface (fur) temperature $\left({ }^{\circ} \mathrm{K}\right), h_{\mathrm{c}}$ is the convection coefficient $\left(\mathrm{Wm}^{-2} /{ }^{\circ} \mathrm{K}\right), T_{\mathrm{a}}$ is the ambient air temperature $\left({ }^{\circ} \mathrm{K}\right), E_{\mathrm{ex}}$ is the heat lost through respiratory evaporation $\left(\mathrm{Wm}^{-2}\right), E_{\mathrm{sw}}$ is heat lost through sweating $\left(\mathrm{Wm}^{-2}\right)$, and $C$ is conductive heat loss $\left(\mathrm{Wm}^{-2}\right)$. An average summer day was a hypothetical 24 hour period in which thermal parameters for each given hour were an average for that hour over the summer. An average adult moose had the average weight of an adult at Isle Royale, $358 \mathrm{~kg}$, and an energy metabolism which was an average of adult male and female metabolisms (Belovsky 1978).

The National Park Service at Isle Royale collected daily summer thermal measurements: maximum-minimum air temperature, relative humidity and wind speed. In addition, measurements of solar radiation, soil temperature, water temperature, vegetation temperature, moose surface temperature, and moose convective, conductive and evaporative heat losses were made and these values appear in the Appendix. In many instances, these data represented crude estimates, but it was felt that their accuracy was sufficient for use in an optimization model.

Only observed moose behaviors and available habitats were used to compute $H S$ values. Moose were observed during the summer either active-feeding or bedded; moose were never observed standing without feeding. Moose also chose the orientation of their body to the sun's path: parallel or perpendicular. While moose were feeding, there did not appear any way for them to consistently orient their bodies while moving from plant to plant. Rather at times they were perpendicular and at others, parallel, providing an averaged orientation.

The environment was arbitrarily divided into four habitat types which appeared important to moose. Beaver ponds were sites for aquatic feeding and were never used for bedding. Conifer forest had a canopy dominated by conifer trees $(>50 \%)$ and was used only as a bedding site in summer, since food plants were rare. Deciduous forest had a canopy dominated by deciduous trees $(\geqq 50 \%)$ and open areas had less than $20 \%$ canopy cover. Open areas provided the majority of moose-food, with well-developed shrub layers which had high nutritional quality due to the absence of shading. Because open areas were relatively small and distributed throughout the deciduous habitat, a moose experienced both habitats in equal proportion while terrestrial feeding in a coarse-grained manner. Consequently, 8 behavior-habitat choices were observed (feeding-open-deciduous, feeding-pond, beddedparallel-open, bedded-perpendicular-open, bedded-perpendiculardeciduous, bedded-parallel-deciduous, bedded-parallel-conifer, bedded-perpendicular-conifer), providing 192 hourly behaviorhabitat choices during an average summer day, if moose "view" their day in discrete hourly periods.

\section{The Model}

The goal was maximization of daily feeding time at the least possible energetic cost, since moose were known to be energy maximizers in their feeding (Belovsky 1978). The limitation of "least possible energetic cost" emerged from contingency models of feeding behavior (Schoener 1974), which predict that an animal should feed in a time period only if the net energy gained by feeding is positive. A corollary is that if an animal is presented with $N$ feeding periods that have positive net energy values for feeding, but the animal can only feed in $X$ periods due to risk factors or digestive capacity ( $N$ greater than $X$ ), then the $N$ minus $X$ periods which have the lowest positive net energy values should be dropped. This follows from the notion that the net energy available to an animal is positively related to its fitness. This approach has been extended by Huey and Slatkin (1976) to theoretically determine when a lizard should move from one micro-habitat to another for passive thermoregulation.

Moose, as herbivores, have constant energetic costs for search and handling within a given environment and net energy available from feeding in any hour should be positive because gross energy intake is a large constant (Belovsky 1978). Therefore, energy expenditure for thermoregulation should determine which hours have greater positive net energy values. Moose $H S$ values deviating from 0 (thermoneutrality) were assumed to require greater energy expenditure for shivering, panting, changes in blood flow, etc., to maintain a constant body temperature or reduce changes and $Q_{10}$ effects on metabolism (Gordon et al. 1968; Schmidt-Nielsen 1975; Whittow 1971). Because all feeding energy values were constants except thermoregulatory costs, relative energy costs for thermoregulation were sufficient for the comparison of hourly behav- 


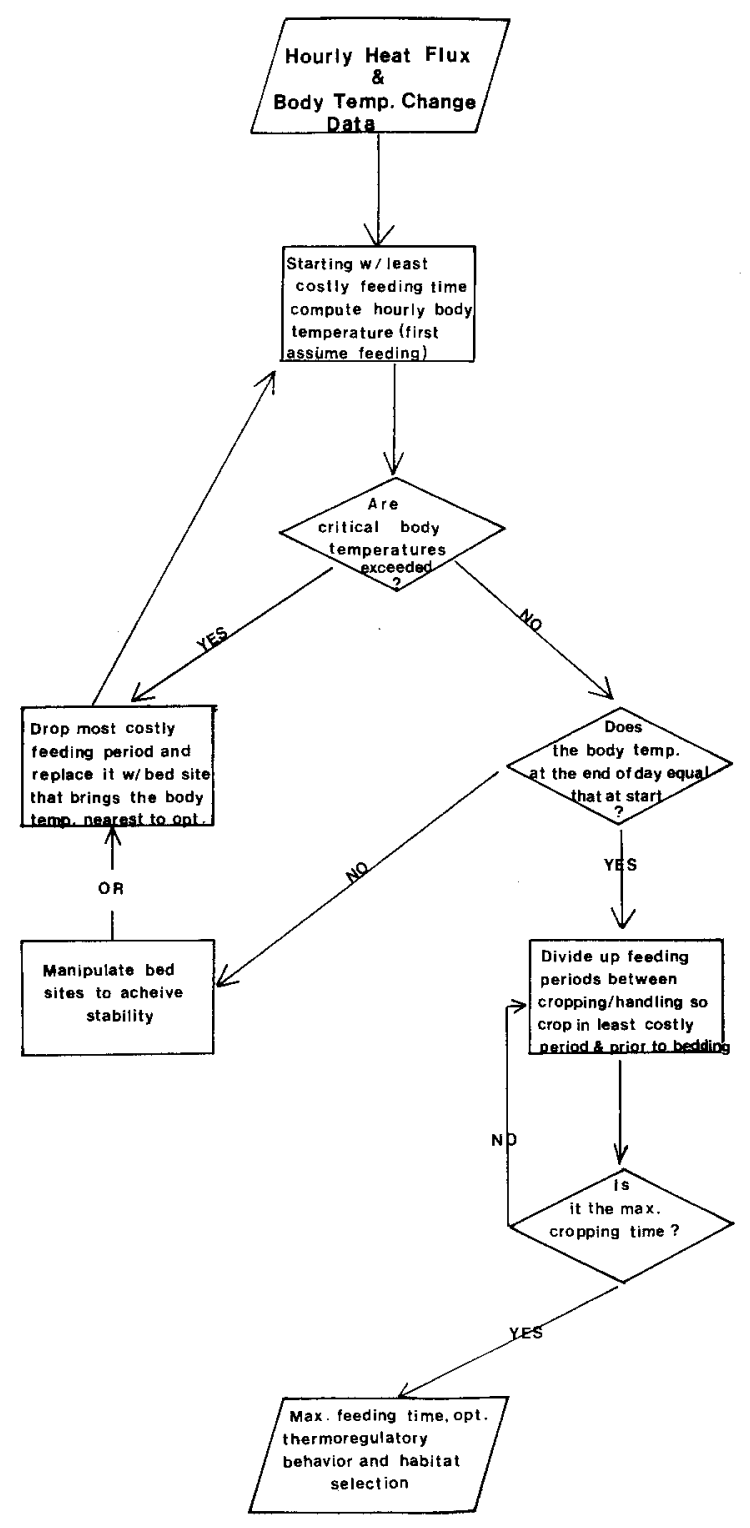

Fig. 1. The flow chart represents the optimization model used to predict a moose's maximum daily feeding time at the least energetic cost on the basis of the constraints presented in the text

ior-habitat choices, and a metabolic index was developed for this purpose.

Several large ungulate metabolism studies (Blaxter 1962; Weiner 1977; Blaxter and Wainman 1961; Brockway and Maloiy 1968) indicated that metabolism increased 2.6 times faster (s.d.= 0.4 ) with negative $H S$ values than with positive, assuming a linear relationship between $H S$ and a metabolism increase (observed metabolism - minimum recorded metabolism). This observation appeared reasonable (linear regression: average $r^{2}=0.95 \pm 0.02$ ). Furthermore, Silver et al. (1971) indicated that large ungulates might possess a linear plot of metabolism versus environmental temperature rather than the conventional curvilinear plot. The metabolic index, based on this information, was:

Metabolic Index $=2.6|H S|, \quad$ if $H S<0$,

and

Metabolic Index $=|H S|, \quad$ if $\quad H S \geqq 0$.
Constraint - Limits to Body Temperature. An animal's body temperature cannot vary beyond lethal upper and lower values. If the animal, however, followed this course, a predator attack or any other unexpected increase in activity when the animal was at its upper body temperature limit would result in death since activity increases body temperature. On the other hand, a storm when the animal was at its lower limit could be lethal. Therefore, it seems likely that an animal will set its upper and lower body temperature limits to provide a 'dead band' or 'margin for error' between normal acceptable limits and the lethal level (Heath 1964; DeWitt 1967).

The easiest way of determining the 'dead band' limits was to permit moose to demonstrate them, when provided with a free choice of thermal environments and behaviors. Knorre (1959) found that Siberian moose in summer allowed their body temperatures to vary from 38.4 to $38.8^{\circ} \mathrm{C}$, a $0.4^{\circ} \mathrm{C}$ variation, when permitted to choose between shaded conditions (bedded in a barn) and open (feeding in a pen). This constraint can be written:

$0.4^{\circ} \mathrm{C} \geqq \sum_{i=1}^{n} \mid H S_{\mathrm{i}} / 57.4 \mathrm{Wm}^{-2} /{ }^{\circ} \mathrm{Cl}$

where $n$ is any time period between 1 and $24 \mathrm{~h}$ later, where all interim periods are included, $57.4 \mathrm{Wm}^{-2}$ is the heat required to change an average adult moose's body temperature $1^{\circ} \mathrm{C}$, and $H S_{\mathrm{i}}$ is the $H S$ value chosen at hour $i$.

Constraint - Steady Periodic Fluctuation of Body Temperature. The short-term steady state or 'climate space' analysis developed by Porter and Gates (1969) and applied successfully by them and others to determine feasible behavior-habitat choices for small animals with short time constants (Morhardt and Gates 1974; Morhardt 1975; Porter et al. 1973, 1975) cannot be applied to moose because of their large body masses which provide long time constants for the heat flow model [Eq. (1)]. This, however, does not negate the importance of a long-term 'steady state' or 'steady periodicity' for moose heat flow. If an animal is to develop a useful strategy for the selection of behavior-habitats, it must be able to repeat the strategy on average, or, sooner or later, the animal will reach a point where any decision might violate its physiological body-temperature limits and result in feedingtime-minimization. This is further complicated when daily variations in climatic conditions are considered, since they require the animal to have sufficient behavior-habitat flexibility to compensate. This constraint, assuming a $24-\mathrm{h}$ periodicity, can be written as:

$0=\sum_{i=1}^{24} H S_{\mathrm{i}}$

Constraint - Digestive Organ Capacity and Food Processing Time. A moose cannot continue to feed if its digestive organ, the rumen, is full or it must regurgitate food for rumination. The digestive organ capacity constraint was presented elsewhere (Belovsky 1978) and was written for the present model as:

32,900 g-wet wt/day $\geqq 62.2 T_{1}+400 T_{\mathrm{a}}$,

where $32,900 \mathrm{~g}$-wet wt/day is the rumen capacity, $T_{1}$ is terrestrial feeding time (min) and $T_{\mathbf{a}}$ is aquatic feeding time. If a moose must drop feeding times because the rumen is full, aquatic times should be deleted since aquatic feeding provides less gross energy intake than does terrestrial feeding (Belovsky 1978). 
To properly digest food, a ruminant must spend time regurgitating the rumen contents and masticating them (Blaxter 1962). A moose was assumed to crop food up to the maximum observed period, $2.1 \mathrm{~h}(\bar{x}=0.9 \pm 0.6, N=7)$ and then to ruminate for a period which satisfied the average observed feeding-to-ruminating ratio, $1 / 1.5$ (observed ruminating time: $\bar{x}=1.3 \mathrm{~h} \pm 0.8, N=7$ ) (Belovsky and Jordan 1978).

Solving the Model. There were $24 \mathrm{~h}$ time periods, each of which had 8 potential behavior-habitat combinations, providing $8^{24}$ potential daily combinations of moose behavior-habitat choices. One combination (or perhaps several equivalent) had to be found which satisfied the constraints and maximized daily feeding time at the least possible energetic cost. The solution was found using an iterative computer program, which reduced the number of iterations on the basis of the optimality theories developed in dynamic programming (Bellman and Dreyfus 1962).

In simplified terms, the program operated by following these steps:

1) The feeding option (terrestrial or aquatic) at each hour which had the lowest metabolic index was chosen and these were ranked according to their metabolic indices (1-lowest to 24-highest).

2) Starting with the moose feeding in all $24 \mathrm{~h}$ periods, it was determined whether or not the 'steady periodic' [Eq.(3)] and body temperature [Eq.(4)] constraints were violated.

3) If these two constraints were violated, the hourly feeding option with the highest metabolic index was replaced with a bedded-behavior-habitat choice which tended to reverse the most recent changes in body temperature at the least possible energetic cost without violating the constraints.

4) This process was continued (return to step 2, except the moose now feeds for only $23 \mathrm{~h}$ periods, $22,21, \ldots$ ), dropping
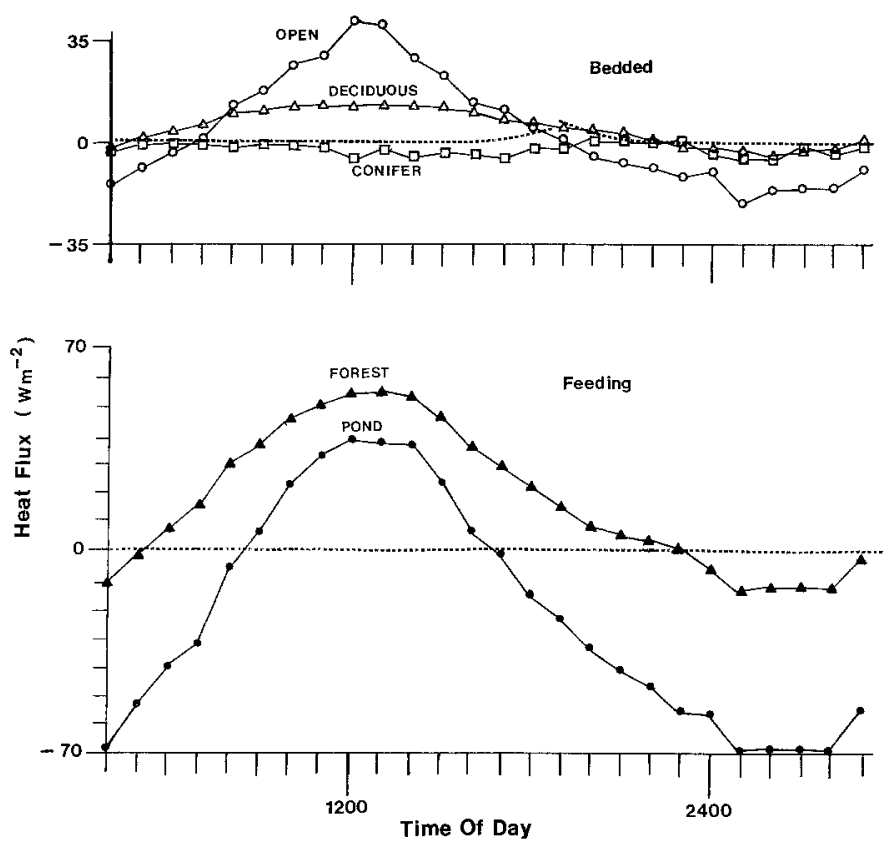

Fig. 2. These graphs present an average adult moose's hourly $H S$ values $\left(\mathrm{Wm}^{-2}\right)$ for an average summer day. The $H S$ values in the upper figure are for moose bedded in open, deciduous and conifer habitats with their bodies oriented perpendicular to the sun's path during daylight hours. The lower graph presents the $H S$ values for moose feeding in a beaver pond or forest. It is assumed that their bodies alternate between parallel and perpendicular orientation thus producing an average orientation to the sun's path during daylight

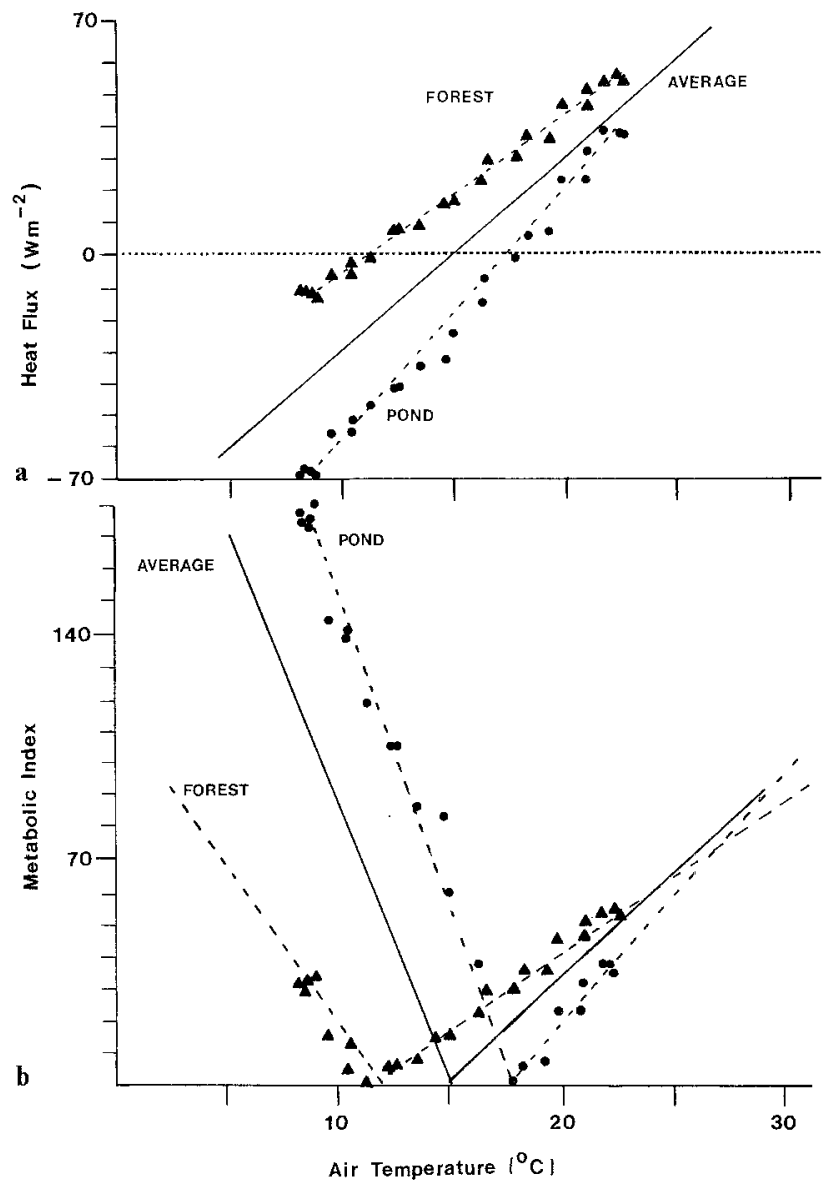

Fig. 3. a Presents a plot of a moose's $H S$ value $\left(\mathrm{Wm}^{-2}\right)$ against the corresponding air temperature $\left({ }^{\circ} \mathrm{C}\right)$ on a given day which was not significantly different from average and for which all necessary thermal parameters were simultaneously measured. The $H S$ values correspond to a moose feeding on land and in a pond; the solid line represents an average of these two feeding behaviors. b Presents a plot of a moose's metabolic index, as computed from the $H S$ values above, versus the observed air temperature. The solid line presents the average index for feeding on land and in a pond

the most costly feeding period and replacing it with a bedded behavior-habitat choice until the 'steady periodic' [Eq.(3)] and body temperature [Eq.(4)] constraints were satisfied.

5) After the 'steady periodic' and body temperature constraints were satisfied, the digestive organ capacity and food processing constraints were applied.

a) Violations of the digestive organ capacity constraint were eliminated by replacing the highest metabolic index aquatic feeding period with the least costly bedded option for the hour.

b) Violations of the ruminating constraint were handled by having the moose ruminate rather than crop for the necessary time period, such that the least amount of potential feeding time was spent ruminating and rumination occurred in feeding times with the highest metabolic index. One manner of accomplishing this was to have cropping always occurring just prior to a bedded period so rumination could occur while the moose was bedded.

6) The 'steady periodic' and body temperature constraints were re-examined at this point for violations. Any violations at this point were usually small and were corrected by making variations in the bedded behavior options previously chosen.

The solution requires many iterations, for moose a minimum of 30 iterations were required. The least costly feeding option 


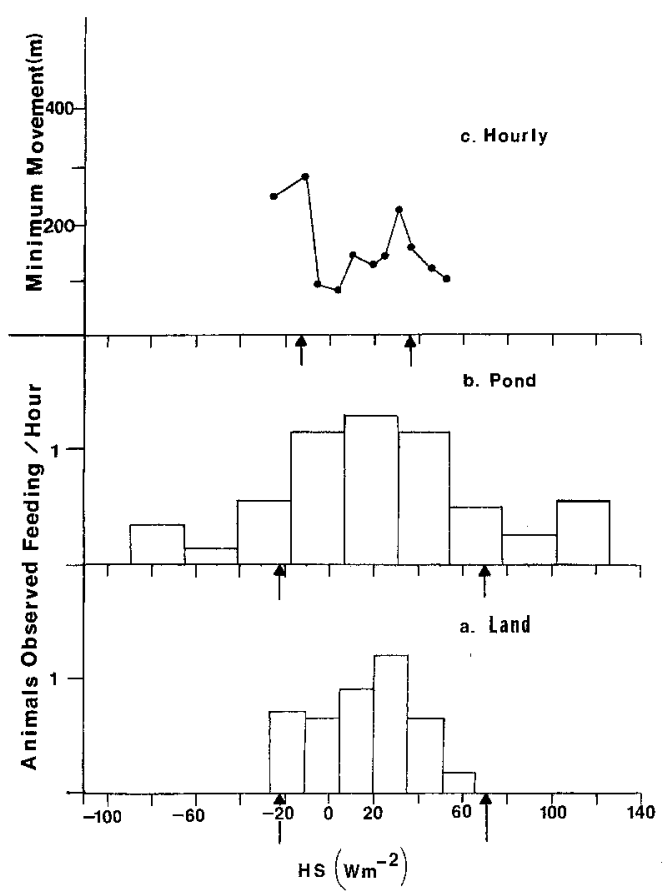

Fig. 4 a-c. The observed distribution of moose feeding on land (a), feeding in water (b) and hourly movement in meters (c) plotted against the $H S$ value for that activity at the time of the observation. The $H S$ values were obtained by using the observed air temperature and the air temperature- $H S$ relationship plotted in Fig. 3, where movement $H S$ values come from an average of terrestrial and aquatic feeding values (Fig. 3). The feeding-on-land plot is based upon 48 observations, feedingin-water plot on 65 observations and the movement data on 69 measurements. At least $5 \mathrm{~h}$ were spent watching for moose feeding at each interval of $H S$ values plotted. The arrows in the graphs represent the $H S$ values where the moose's metabolic index equals 70 for terrestrial and aquatic feeding and 35 for the movement plot

was terrestrial feeding between 2100 and 2200 ; this was the feeding time that was never dropped and from which all constraint calculations were started.

\section{Results and Discussion}

Figure 2 presents the hourly $H S$ values for 5 of 8 behavior-habitat combinations during an average summer day. Figure 3 illustrates the close correlation between air temperature and the simultaneously computed $H S$ values for feeding moose (terrestrial: $r^{2}=0.92$, $N=24$; aquatic: $r^{2}=0.86, N=24$ ). Also, presented in Fig. 3 is the relationship between metabolic index and air temperature. These plots were based upon thermal parameters that were collected simultaneously over a $24-\mathrm{h}$ period.

Figures $4 \mathrm{a}$ and $\mathrm{b}$ present the observed feeding per hour of observation and Fig. $4 \mathrm{c}$ the mean distance travelled per hour by moose at different $H S$ values. The $H S$ ranges used in each histogram class encompassed the observed average hourly change. All $H S$ values were computed using the air temperature- $H S$ correlations in Fig. 3 and air temperatures measured during the observational period.

Peaks of hourly feeding on land and water (Fig. $4 \mathrm{a}$ and b) occurred at similar $H S$ values, 20 and $22 \mathrm{Wm}^{-2}$. This is somewhat surprising, since zero $H S$ values (thermoneutrality) are considered better, but $H S$ values in themselves might not be all important because they also have a cumulative effect. The feeding distribu-

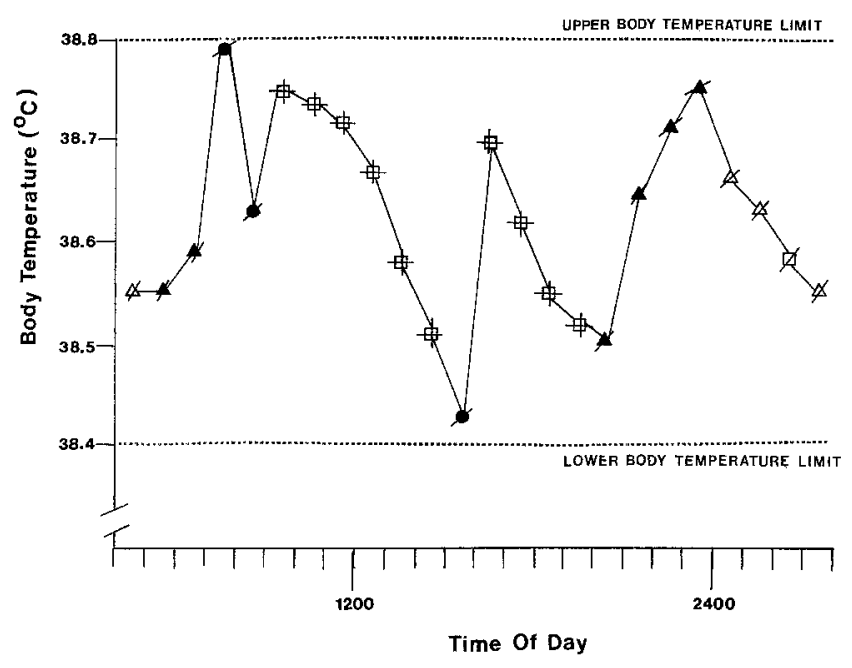

Fig. 5. The solution to the optimization model is presented in this graph. Prior to the imposition of rumen capacity and rumination time constraints, a moose has $9 \mathrm{~h}$ in which to feed. The solid symbols represent times suitable for feeding, while open symbols represent bedded times. The deciduous habitat is represented by a $\Delta$, the conifer by a $\square$, and a beaver pond by a $\circ$. X's represent a parallel body orientation to the sun's path (none predicted), t's a perpendicular orientation and I $\mathrm{s}$ an average between the parallel and perpendicular (the effect of orientation becomes unimportant). The manner in which a moose's body temperature changes as a result of its predicted behavior-habitat choice at each hour is presented and compared with the observed minimum and maximum body temperature limits observed for captive moose given a free-choice of habitat and activity (Knorre, 1959)

tions were skewed towards positive $H S$ values. The skewness might have emerged because positive $H S$ values had lower metabolic indices per $\mathrm{Wm}^{-2}$ deviation from zero than did negative values; an index of 70 and less encompassed $100 \%$ of terrestrial feeding and $80 \%$ of aquatic observations.

An alternative explanation for peak feeding and a skewness towards positive $H S$ values was that moose 'keyed' their feeding to dawn and dusk, so light aided in the visual search for food, even though thermal conditions were slightly less advantageous. However, this was unlikely since moose have notoriously poor vision (Peterson 1955) and from observation, moose seemed to rely upon smell and taste to locate foods; e.g., aquatic feeding was done with the eyes closed. Furthermore, over the summer, $H S$ values at peak feeding occurred any time from $4-5 \mathrm{~h}$ before or after sunset or sunrise depending upon the date and weather conditions.

Hourly movement (Fig. 4c), synonymous with feeding periods, increased to a maximum as $H S$ values either increased or decreased from zero and then movement decreased again. As $H S$ approached zero, moose fed intensively, reducing movement; however, as HS departed from zero and metabolism increased, moose shuttled between habitats to increase feeding time by using different habitats and behaviors for thermoregulation. Finally, as $H S$ continued to depart from zero and metabolism increased, moose remained bedded (sought shade or cover) for longer periods to avoid excessive $H S$ values. Furthermore, the asymetry of $H S$ versus behavior, as discussed above, was also apparent in the movement plots (peak movement at -10 and $24 \mathrm{Wm}^{-2}$ ) and could be accounted for by metabolic indices of 35 .

Figure 5 presents the solution to the optimization model at each hour of an average summer day, prior to the imposition of digestive capacity and rumination constraints. There were $9 \mathrm{~h}$ 


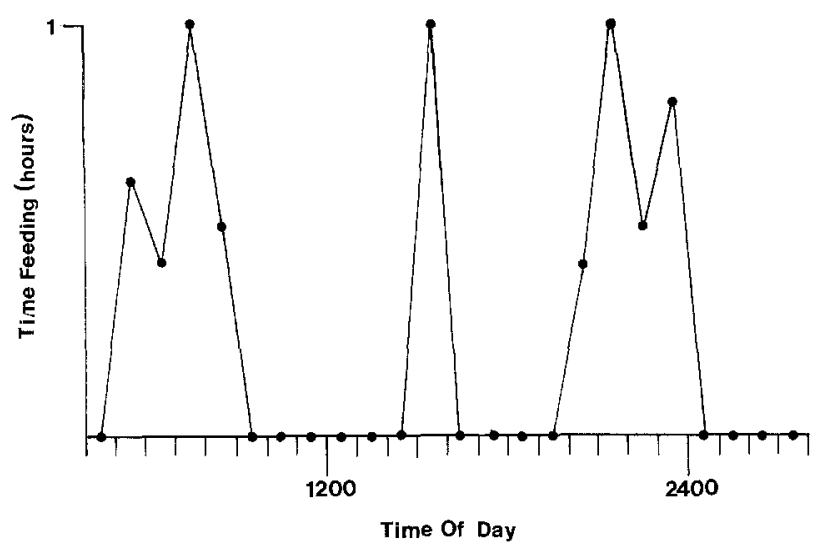

Fig. 6. This plot presents the predicted daily activity cycle for an average moose in summer. The fraction of each hour a moose is predicted to feed is plotted against the time of day

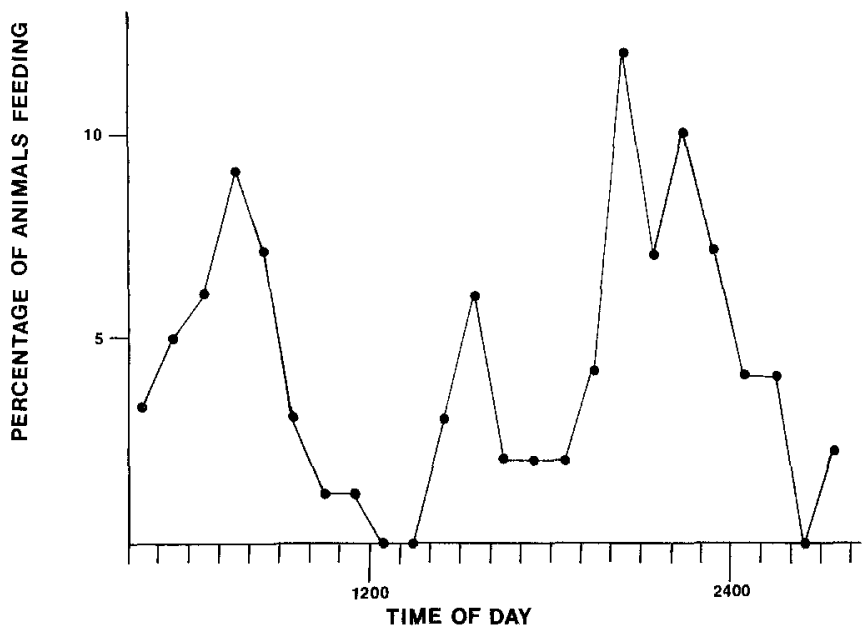

Fig. 7. A plot of the observed moose summer activity at Isle Royale National Park, Michigan. The plot is based upon 194 observations of feeding moose and presents the percentage of all animals observed feeding (194) that were observed at a given hour (Belovsky and Jordan, 1978)

suitable for moose feeding-related activities (cropping and ruminating): $3 \mathrm{~h}$ in water and 6 on land. After rumination (Fig. 6), there would be $150 \mathrm{~min}$ in ponds and $256 \mathrm{~min}$ on land for cropping. The fraction of each hour of an average summer day spent cropping compared very well with the observed cropping peaks and their duration, comparison of Fig. 6 and 7 (0500-0900, 15001600 and $2000-2400$ ).

Moose were predicted to have less aquatic cropping time because the night, dawn and dusk provided on average thermal conditions which led to excessive heat losses due to the high conductivity of water; and during the warmer midday period, despite the high conductivity of water, excessive heat gain resulted from too much solar radiation due to the openness of the ponds. Therefore, only very limited periods of the day were acceptable for aquatic cropping and provided metabolic indices less than those for terrestrial feeding at the same hour.

The average adult moose must drop some cropping times because of the digestive organ constraint. Belovsky (1978) demonstrated, using an energy-maximizing feeding model, that an average Isle Royale adult moose should drop $107 \mathrm{~min}$ of available aquatic cropping time, but no terrestrial cropping time. Because of higher metabolic indices, aquatic cropping at $0700-0800$ and $1500-1600$ should be reduced to satisfy the digestive organ constraint, but the amount of reduction during each hour could not be estimated since both hours have virtually identical metabolic indices for aquatic feeding. Both periods, however, had less aquatic cropping than expected from the model without considering the digestive organ constraint.

A goodness of fit test between the model's predicted cropping times (Fig. 6) and observed times (Fig. 7) demonstrated no statistical difference $\left(\mathrm{X}^{2}=2.74, p \leqq 0.10\right.$, d.f. $=2$ : for three time classes $0500-0900,1500-1600$ and $2000-2400,159$ cropping observations). The test was only done for periods in which the model predicted cropping since the presence of a small amount of cropping (18\%) in periods not predicted resulted in a $\mathrm{X}^{2}$ value of $\infty$.

Table 1 presents observed and the model's predicted habitat utilizations, along with the abundances of each habitat in the study area, based upon a point sampling of the environment. The open habitat was combined with the deciduous forest since open areas were small patches in the forest beyond the resolution of the radio-telemetry-map system used to collect the data. Consequently, moose were found to have chosen habitats in a nonrandom manner $\left(\mathrm{X}^{2}=17.24, p<0.005\right)$ which was not different from the model's predictions $\left(\mathrm{X}^{2}=0.06, p<0.05\right)$.

Observed and predicted bed habitats (Table 2) and orientations (Table 3) were important aspects of thermoregulation and feedingtime-maximization in the model). The observed bed habitats did

Table 1. A comparison of the observed abundance of various habitats at Isle Royale National Park with the observed and predicted habitat utilization by moose in summer (number of observations)

\begin{tabular}{lclc}
\hline Habitat & Abundance & \multicolumn{2}{l}{ Utilization by moose in summer } \\
\cline { 3 - 4 } & & Observed & Predicted \\
\hline Conifer & 15 & 29 & 10 \\
Deciduous & 61 & 30 & 11 \\
Pond & 3 & 9 & 3 \\
\hline
\end{tabular}

Table 2. Moose habitat selection for bedding sites compared with the predicted bedding site from the model and the abundance of sites in the environment (number of observations)

\begin{tabular}{lccc}
\hline Bedding site & Abundance & \multicolumn{2}{l}{ Utilization of bedding sites } \\
\cline { 3 - 4 } & & Observed & Predicted \\
\hline Conifer & 15 & 11 & 11 \\
Deciduous & 61 & 1 & 4 \\
Open & 4 & 0 & 0 \\
\hline
\end{tabular}

Table 3. A comparison of the observed orientation of moose beds in relation to the sun's path (perpendicular vs. parallel) with the orientation predicted by the model (number of observations)

\begin{tabular}{lcc}
\hline Orientation & Observed & Predicted \\
\hline Perpendicular & 27 & 12.5 \\
Parallel & 6 & 2.5 \\
\hline
\end{tabular}


not appear to have been chosen randomly $\left(\mathrm{X}^{2}=57.39, p<0.05\right)$ and were not statistically different from the predicted bed habitats $\left(\mathrm{X}^{2}=1.40, p<0.50\right)$. The model predicted that all daytime beds should be perpendicular to the sun's path to reduce the moose's surface area exposed to direct solar radiation. This was important, even though no beds were predicted in the open, since most forest areas had a sufficiently open canopy to allow body orientation to influence the solar radiation striking a moose. Nocturnal beds, however, should not be influenced by orientation and should, therefore, be randomly oriented between the parallel and perpendicular. Observed and predicted bed orientations were not statistically different $\left(\mathrm{X}^{2}=0.03, p<0.85\right)$.

43 of 72 hourly habitat observations from radio-collared moose agreed with the model's hourly predictions; this amount of random agreement was highly unlikely (binomial probability: $1 / 3$ because of three potential habitat choices, $p<0.001$ ). Furthermose, a chisquared contingency test indicated that the model's hourly predictions were not statistically different from the hourly moose observations $\left(\mathrm{X}^{2}=17.67\right.$, d.f. $\left.=23, p<0.75\right)$. Of the three days on which moose were tracked hourly, one day was not statistically different from the average ( 20 of 24 habitat choices agreed), one day was almost different (part of day was cloudy and rainy: 16 of 24 habitat choices agreed with the model's predictions), and the third day was statistically different from the average at each hour (cloudy, rainy and cold: 7 habitat choices agreed with the model's predictions).

Several simpler decision-making models were constructed for comparative results. One model attempted to minimize hourly body temperature changes, a second minimized the hourly metabolic index and a third allowed moose to shuttle between feeding and bedding at each hour to minimize body temperature changes. All three provided a moose with less feeding time than required to crop sufficient food for energy requirements.

There was no way to explain how moose might make a complicated set of decisions which were consistent with the model. One decision-making method was ruled out: moose could not base decisions on whether or not thermal conditions at any one hour satisfied the constraints (i.e., is it 'too hot or cold'), since this could exclude one or more future feeding periods with a lower energetic cost and, at day's end, the maximum amount of feeding time might not be attained.

An alternative, similar to the 'too hot or cold' mechanism, could provide behavior similar to that predicted by the model: if moose anticipated future hourly-thermal conditions based upon present conditions, they could 'decide' whether it might be better to presently feed or wait for some future period. This is plausible because hourly-thermal parameters have a daily pattern (see Appendix), such that given conditions at time $X$, there is a large probability that at hour $X+N$, where $N$ is less than $24 \mathrm{~h}$, thermal conditions can be approximated. Moose could accomplish this using a set of maximum-minimum thermal conditions as limits for acceptable feeding which varied from day to day with changing thermal conditions and could be either 'learned' or physiologically set.

\section{Conclusion}

Modifying the 'steady-state' thermodynamic equations (Porter and Gates 1969) to transient equations for an animal's heat flux, and establishing a likely goal and set of constraints on behavior, a model of optimal thermoregulatory behavior was developed for moose. The goal was maximization of a moose's daily feeding time at the least possible energetic cost. The constraints were a 'steady periodic' fluctuation in body temperature, upper and lower body temperature limits, and rumination and digestive organ capacity limits on feeding. The model's solution was consistent with a moose's observed summer behavior, on average. The model's predictions did not present what a moose should do, given free-choice, but what it should do given the observed behavior flexibility, as potential but unobserved behaviors were not included in the model.

Standing without feeding was a likely behavioral alternative, but was never observed; because, when heat gain posed a problem, conductive heat losses while bedded exceeded the increased convection while feeding. Furthermore, when heat loss posed a problem, conduction while bedded reduced losses, while standing increased convective losses. Standing increased convective heat loss because more body surface was exposed to wind.

If moose followed the model's decision criteria, fitness would be increased because feeding-time maximization at the least possible energetic cost would increase food supply by reducing minimum-required food quality and increasing potential daily food consumption, and would provide greater net energy per unit of feeding time.

The generality of these results for other animals depends upon the importance of predation, interference competition, variability in the thermal environment and/or food processing constraints. As these conditions change, an animal may find it more and more difficult to maximize feeding time. Nevertheless, the thermoregulatory criteria employed in the model should apply to periods chosen for feeding, after all other limits are satisfied. Therefore, the model should apply in varying degrees to most animals.

Acknowledgments. I wish to thank T.W. Schoener, C.R. Taylor and R.D. Stevenson for comments on an earlier manuscript. D. Gates provided invaluable criticism and aid during the field studies and W. Porter provided a detailed review which was most helpful. This work was made possible by field assistants who worked long hours: J. Cannon, P. Spiro, J. Slade, D. Pletcher and D. Johnson. This work was supported by funds from the Environmental Education Fund, the Richmond Society, Harvard University and the Harvard Society of Fellows.

\section{Appendix: Data Used in Computing HS}

The hourly observed air, soil, vegetation and water temperatures and vapor pressure deficits could be predicted using the equations:

$V_{\mathrm{i}}=V_{\min }+\left(V_{\max }-V_{\min }\right) \cos ^{1} / 2 \pi\left(1-t_{\min } / 10\right)$,

for the period $0400-1400$, and:

$V_{\mathrm{i}}=V_{\max }-\left(V_{\max }-V_{\min }\right) \cos ^{1} / 2 \pi\left(1-t_{\max } / 14\right)$,

for the period $1400-0300$, where $V$ was the value of concern at time $i, V_{\max }$ was the daily maximum value, $V_{\min }$ was the daily minimum value and $t$ was the time of day with the maximum (1400) and minimum $(0400)$ values. The hourly solid and vegetation temperatures $\left(T_{\mathrm{v}-\mathrm{g}}\right)$ were measured with a surface temperature probe. $96 \%$ of observed variation in hourly values was explained by the equations over a 10 day period. Hourly values for an average summer day were computed using the equations and the maximum-minimum values in Table A.

Long and shortwave radiation were not measured at the Isle Royale weather station; consequently, a simple net radiometer was constructed using a flat-black aluminum cylinder $(12 \mathrm{~cm}$-dia., $16 \mathrm{~cm}$-length) with a known emissivity (0.97-3 M paint). The cyclinder was positioned parallel to the sun's path and shielded from the wind. Total long and short- 
Table A. Thermal parameters used in calculating the conditions on an average summer day at Isle Royale

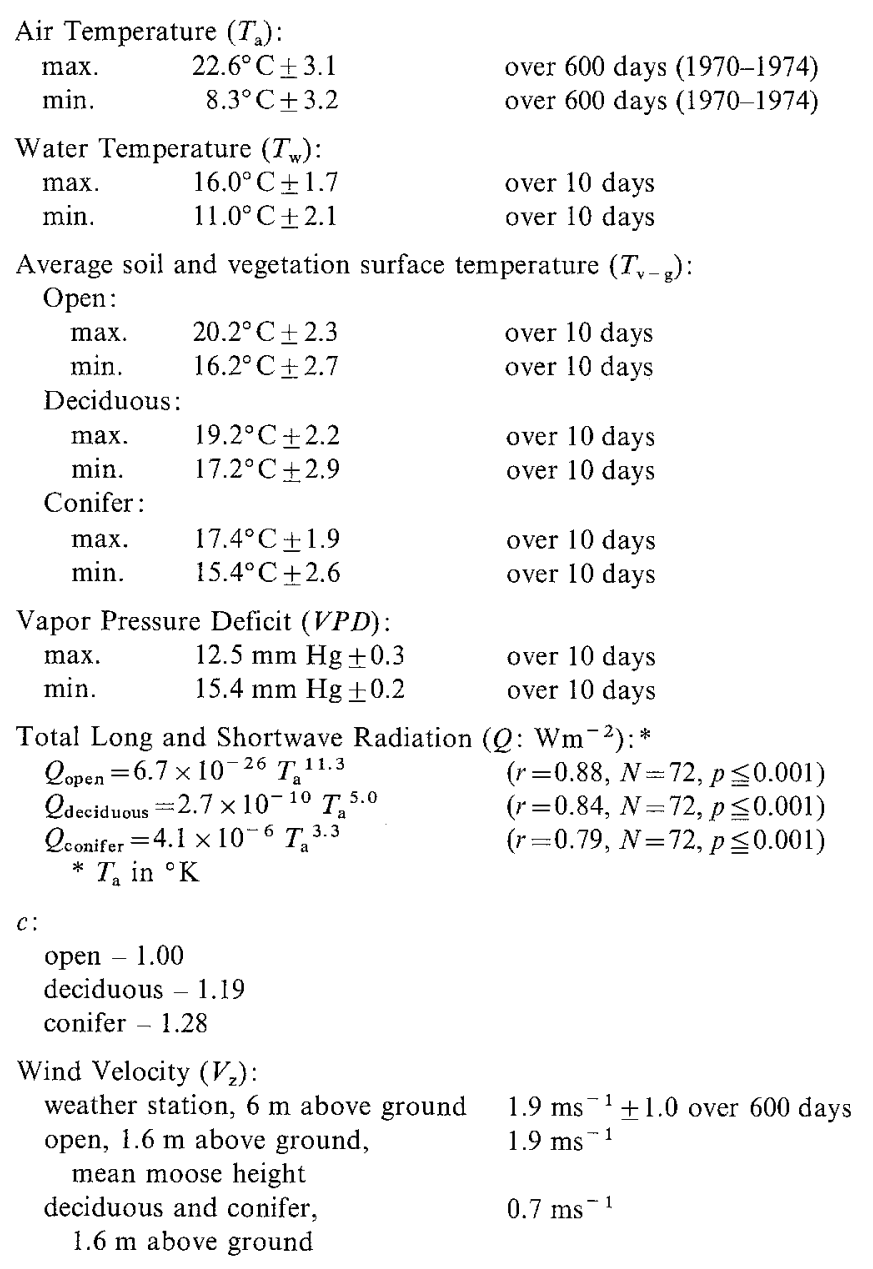

wave radiation striking the cylinder, assuming thermodynamic equilibrium, was computed as:

$Q=\varepsilon \gamma(B B)^{4}+h_{\mathrm{c}}\left(B B-T_{\mathrm{a}}\right)$

where $Q$ was net long and shortwave radiation $\left(\mathrm{Wm}^{-2}\right), \gamma$ was the Stefan-Boltzman constant, $\varepsilon$ was the emissivity $(0.97), B B$ was the cylinder's temperature $\left({ }^{\circ} \mathrm{K}\right), h_{\mathrm{c}}$ was the free convection coefficient $\left(0-2.4 \mathrm{Wm}^{-2}\right.$ : Monteith, 1973), and $T_{\mathrm{a}}$ was the air temperature $\left({ }^{\circ} \mathrm{K}\right) . B B$ was the cylinder's surface temperature measured as the air temperature within the cylinder. $Q$ was measured at each hour over 3 days in open, deciduous and conifer habitats, and correlated with air temperature (regressions in Table A).

Knowing longwave radiation, $Q$ was separated into its shortwave component:

$T S=1 / a\left(Q-\gamma \varepsilon c\left(0.5 T_{\mathrm{v}-\mathrm{g}}+0.5 T_{\mathrm{a}}\right)^{4}\right)$,

where $T S$ was shortwave radiation $\left(\mathrm{Wm}^{-2}\right), a$ was the shortwave absorptivity of the painted surface $(0.8-3 \mathrm{M}$ paint), and $c$ was a multiple determined experimentally when shortwave radiation was not present to account for the vegetation's 'insulating' effect (values in Table A). $T S$ was allocated between direct and diffuse sources:

$S=\frac{T S}{(0.24)(0.9)+(0.5)(0.1)}$

and:

$s=0.1 \mathrm{~S}$, where $S$ was direct shortwave radiation $\left(\mathrm{Wm}^{-2}\right), s$ was diffuse shortwave radiation $\left(\mathrm{Wm}^{-2}\right), 0.24$ was the cylinder's solar profile (Monteith 1973), 0.9 was the fraction of TS which was direct (Morhardt and Gates 1974), 0.1 was the fraction of TS which was diffuse (Morhardt and Gates 1974), and 0.5 was the fraction of surface area exposed to diffuse shortwave radiation.

The radiation values for an average summer day were computed using average hourly air temperatures and the $T_{\mathrm{a}}$ versus $Q$ regressions (Table A). This technique estimated shortwave radiation values within $10 \%$ of values measured with a pyranograph and gave total radiation values comparable with the average total radiation over 16 summer days in similar habitats (Lull and Reigner 1967).

Radiation absorbed by a moose $\left(Q_{\text {abs }}: \mathrm{Wm}^{-2}\right)$ was calculated as (Porter and Gates 1969):

$Q_{\mathrm{abs}}=a z S+0.5\left(a s+a r(S+s)+\varepsilon \gamma c\left(0.5 T_{\mathrm{a}}+0.5 T_{\mathrm{v}-\mathrm{g}}\right)\right)^{4}$,

where $a$ was the absorptivity of a moose's surface for shortwave radiation and was assumed to be 0.74, the same as a brown cow (Blaxter 1962; Porter and Gates 1969; Riemerschmid and Elder 1945), $z$ was the fraction of a moose's surface area exposed to direct shortwave radiation: 0.27 when parallel to the sun's path and 0.10 when perpendicular (average adult moose's dimensions and Monteith, 1973), and $r$ was the reflectivity of the environment to shortwave radiation, 0.2 (soil, vegetation and average for water: Monteith 1973).

The moose's surface temperature, $T_{\mathrm{r}}\left({ }^{\circ} \mathrm{K}\right)$, was measured by inserting thermal probes just under the fur tips at six locations and averaging. This was done by immobilizing moose with succinyl-choline chloride. Although this was not an error-free measure since fur is a porous media, making it partly transparent to infra-red radiation, the measure was no worse than those obtained using a radiometer because this instrument is susceptible to the same problem in addition to the problems of the instrument's angle to the fur surface and its field of view (Cena and Clark 1973; W. Porter pers. comm.). Nevertheless, $T_{\mathrm{r}}$ was approximated and was found to be related to radiation absorbed by a moose $\left(Q_{\text {abs }}\right)$ :

$T_{\mathrm{r}}=32.6\left(Q_{\mathrm{abs}}\right)^{0.25}-120.5$,

$(r=0.91, N=7, p<0.001)$. The regression provided moose $T_{\mathrm{r}}$ values similar to those measured for other mammals with a radiometer under identical thermal conditions (Gates 1972; Finch 1972a, b; Morhardt and Gates 1974).

Moose metabolic heat production $\left(M: \mathrm{Wm}^{2}\right)$ was approximated as:

$M=3.6 \mathrm{~b} \mathrm{~W} \mathrm{~W}^{0.75} / 54.9 \mathrm{~m}^{2}$

where $W$ was the moose's body mass ( $358 \mathrm{~kg}$ for an average adult), $3.6 b$ was a constant dependent upon activity (Kleiber 1961), where $b$ was 1.5 for resting and 2.1 for feeding (Moen 1973: based upon deer and sheep), and $5.9 \mathrm{~m}^{2}$ was the moose surface area based upon Moen's (1973) surface-to-body mass relationship for deer.

A moose's convection coefficient $\left(h_{\mathrm{c}}\right)$ was computed using Mitchell's (1976) characteristic dimension equation (body mass of $358 \mathrm{~kg}$ ):

$h_{\mathrm{c}}=7.86 V_{\mathrm{z}}^{0.60}$,

where $V_{z}$ was wind speed at height $z$ above the ground. $V_{z}$ values appear in Table A for an average summer day, as measured at $6 \mathrm{~m}$ above the ground in the open by the Isle Royale weather station and estimated for other heights and habitats using Seller's (1965) heightvelocity equations.

A moose's conductive heat loss $\left(C: \mathrm{Wm}^{-2}\right)$ was dependent upon the relationship:

$C=f k\left(T_{\mathrm{r}}-T_{*}\right) / d$

where $k$ was the conduction coefficient (Schmidt-Nielsen, 1975:2.5 $\mathrm{Wm}^{-2}$ $\left({ }^{\circ} \mathrm{K} / \mathrm{cm}\right)^{-1}$ for air while bedded and $58.7 \mathrm{Wm}^{-2}\left({ }^{\circ} \mathrm{K} / \mathrm{cm}\right)^{-1}$ for water), $d$ was the distance between the moose and the other conducting medium $(0.5 \mathrm{~cm}$ of air while bedded against the soil-vegetation and $3 \mathrm{~cm}$ of water while in a pond, as determined with hide samples), $T_{*}$ was the 
temperature of the conducting medium $\left({ }^{\circ} \mathrm{K}\right)$, and $f$ was the fraction of the moose's surface in contact with the conducting medium $(0.2$ while bedded and $0.2-0.35$ while in a pond, as estimated by observing moose.

A moose's evaporative heat loss was primarily a function of respiratory water loss since moose, as cervids, do not normally sweat (Irving 1964). Using binoculars at distances of $3-5 \mathrm{~m}$ to measure a moose's respiration rate (breaths/min) and simultaneously recording air temperature as an estimate of thermal conditions, a function relating respiration rate to air temperature was found $\left(r^{2}=0.89, N=15, p<0.001\right)$. Using this function, as well as an estimate of a moose's tidal volume based upon Schmidt-Nielsen's (1975) body mass-tidal volume regression and the assumption that a moose's body temperature is an average of $38.6^{\circ} \mathrm{C}$ (Knorre 1959), the respiratory evaporative heat loss $\left(E_{\mathrm{ex}}: \mathrm{Wm}^{-2}\right)$ was estimated to be:

$E_{\text {ex }}=V P D(0.28) e^{0.07} T_{\mathrm{a}}$,

where $V P D$ was the vapor pressure deficit $(\mathrm{mm} \mathrm{Hg})$.

\section{References}

Bellman RE, Dreyfus SE (1962) Applied dynamic programming. Princeton New Jersey Princeton Univ Press

Belovsky GE (1978) Diet optimization in a generalist herbivore: the moose. Theor Pop Biol 14:105-134

Belovsky GE, Jordan PA (1978) The time-energy budget of a moose. Theor Pop Biol 14:76-104

Blaxter KL (1962) The energy metabolism of ruminants. Hutchinson Ltd. London

Blaxter KL, Wainman JW (1961) Environmental temperature and the energy metabolism and heat emission of steers. J Agric Sci $56: 81$

Brockway JM, Maloiy GMO (1968) Energy metabolism of the red deer. J Physiol 194:22-24

Cena K, Clark JA (1973) Thermal radiation from animal coats: coat structure and measurements of radiative temperature. Phys Med Biol $18: 432-443$

DeWitt CB (1967) Precision of thermoregulation and its relation to environmental factors in the desert iguana, Dipsosaurus dorsalis. Physiol Zool 40:19-66

Finch VA (1972a) Thermoregulation and heat balance of the East African eland and hartebeest. Amer J Physiol 222: 1374-1379

Finch VA (1972b) Energy exchanges with the environment of two East African antelopes, the eland and the hartebeest. Symp Zool Soc London 31:315-326

Gates DM (1969) Infrared measurement of plant and animal surface temperature and their interpretation. In: P.L. Johnson (ed) Remote sensing in ecology. Athens Georgia Univ of Georgia Press, p 95-107

Gordon MS, Bartholomew GA, Grinnel AD, Jørgensen CB, White FN (1968) Animal function: principles and adaptation. London: MacMillan Co

Heath JE (1964) Reptilian thermoregulation: evaluations of field studies. Science 146:784-785

Huey R, Slatkin M (1976) Costs and benefits of lizard thermoregulation. Quart Rev Biol 51:363-384

Irving L (1964) Terrestrial animals in cold: birds and mammals. In:
Handbook of physiology DB Dill (ed), Sec 4 Washington DC. : Amer Physiol Soc p 361-378

Kleiber M (1961) The fire of life. John Wiley, New York

Knorre EP (1959) Ecology of the moose. Trans of the Pechora-Illych State Game Preserve, U.S.S.R. GA Novikow (ed). (Translated from the Russian by the Canadian Bureau of Indian Affairs) Syktyvkar, USSR Komi Book Publishers

Lull HW, Reigner IC (1967) Radiation measurements: by various instruments in the open and in the forest. US Forest Serv Res Pap NE-84

Mitchell JW (1976) Heat transfer from spheres and other animal forms. Biophys J 16:561-569

Moen A (1973) Wildlife ecology. San Francsico: WH Freeman Co

Monteith JL (1973) Principles of environmental physics. American Elsevier Publishing Co, Inc. New York

Morhardt SS (1975) Use of climate diagrams to describe microhabitats occupied by Belding ground squirrels and to predict rates of change of body temperature. In: Perspectives in biophysical ecology (eds) Gates D, Schmerl RB. Springer-Verlag, Berlin Heidelberg New York p 303-324

Morhardt SS, Gates D (1974) Energy-exchange analysis of the belding ground squirrel and its habitat. Ecol Mono 44:17-44

Peterson RL (1955) North American moose. Toronto: Univ of Toronto Press

Porter WP, Gates D (1969) Thermodynamic equilibria of animals with environment. Ecol Mono 39:227-244

Porter WP, Mitchell JW, Beckman WA, DeWitt CB (1973) Behavioral implications of mechanistic ecology: thermal and behavioral modelling of desert ectotherms and their microenvironment. Oecologia (Berl) 13:1-54

Porter WP, Mitchell JW, Beckman WA, Tracy CR (1975) Environmental constraints on some predator-prey interactions. In: D Gates, RB Schmerl (eds) Perspectives in biophysical ecology. Springer-Verlag, Berlin Heidelberg New York p 347-364

Pyke GH, Pulliam HR, Charnov EL (1977) Optimal foraging: a selective review of theory and tests. Quart Rev Biol 55:137-154

Riemerschmid G, Elder JS (1945) The absorptivity for solar radiation of different coloured hairy coats of cattle. Onderstepoort J Vet Sci Animal Ind 20:223-234

Schmidt-Nielsen K (1975) Animal physiology: adaptation and environment. London: Cambridge Univ Press

Schoener TW (1969) Optimal size and specialization in constant and fluctuating environments: an energy-time approach. Brookhaven Symp Biol 22:103-114

Schoener TW (1971) Theory of feeding strategies. Ann Rev Ecol Syst 2:369-403

Schoener TW (1974) The compression hypothesis and temporal resource partitioning. Proc Nat Acad Sci $71: 4169-4172$

Sellers WD (1965) Physical climatology. Chicago: Univ of Chicago

Silver H, Holter JB, Colovos HF, Hayes HH (1971) Effect of falling temperature on heat production in fasting white-tailed deer. J Wildl Manage 35:37-46

Weiner J (1977) Energy metabolism of the roe deer. Acta Theriol 22:3-24 Whittow GC (1971) Ungulates. In: G.C. Whittow (ed) Comparative physiology of thermoregulation. Academic Press, New York. p 192283

Received January 2, 1979 